\title{
Clinical Implications of Micrometastasis Detection in Internal Mammary Nodes of Breast Cancer Patients
}

\author{
Jian Zeng Huazhi Xie Yunfei Lu Zhenbo Feng Fu Li \\ Department of Surgery, First Affiliated Hospital of Guangxi Medical University, Nanning, China
}

\section{Keywords}

Breast cancer - Internal mammary nodes · Micrometastasis . Step-serial sectioning

\section{Summary}

Background: The aim of this study was to assess the efficiency of step-serial sectioning (SSS) combined with hematoxylin and eosin (H\&E) and immunohistochemical (IHC) staining in detecting micrometastasis of internal mammary lymph nodes (IMLNs). Patients and Methods: 135 IMLNs from 88 breast cancer patients were re-examined by SSS, combined with either H\&E or IHC staining of the biomarkers cytokeratin-19 and epithelial membrane antigen. Results: Of the 135 IMLNs, 6 nodes from 5 cases displayed 1 or more micrometastases. Histological grade and lymphovascular invasion status were significantly correlated with micrometastasis in the IMLNs ( $p=0.018$ and 0.001 , respectively). Of the 6 nodes positive for micrometastasis, 1 node was detected by both $\mathrm{H} \& \mathrm{E}$ and $\mathrm{IHC}$ staining. The remaining 5 nodes from 4 cases showed evident tumor cells only by IHC staining. Finally 8 of the 83 patients $(9.64 \%)$ without IMLN metastasis showed distant metastasis, while 2 of the 5 patients $(40 \%)$ with IMLN metastasis showed distant metastasis within 28 months of operation. Conclusion: SSS combined with $\mathrm{H} \& \mathrm{E}$ and $\mathrm{IHC}$ staining is more efficient in detecting micrometastasis than classic routine single-slice $\mathrm{H} \& \mathrm{E}$ only.

\section{Introduction}

Breast carcinoma is the most common malignancy in women worldwide and the second leading cause of cancer death in women $[1,2]$. With the aging of society and changes in lifestyle, the incidence of breast cancer is increasing all over the world, especially in developing countries including China [3].

\author{
Schlüsselwörter \\ Mammakarzinom - Mammaria-interna-Lymphknoten . \\ Mikrometastasen · Step-Serial Sectioning
}

\section{Zusammenfassung}

Hintergrund: Ziel dieser Studie war die Bestimmung der Effizienz des Step-Serial Sectioning (SSS) kombiniert mit Hämatoxylin-Eosin (H\&E)-Färbung bzw. immunhistochemischer (IHC) Färbung zur Detektion von Mikrometastasen in den Mammaria-interna-Lymphknoten. Patientinnen und Methoden: 135 Mammaria-interna-Lymphknoten von 88 Mammakarzinompatientinnen wurden mittels SSS kombiniert mit H\&E- bzw. IHC-Färbung erneut auf die Biomarker Cytokeratin-19 und epitheliales Membranantigen untersucht. Ergebnisse: Von den 135 Mammaria-interna-Lymphknoten zeigten 6 Knoten von 5 Fällen eine oder mehrere Mikrometastasen. Der histologische Grad und lymphovaskuläre Invasionsstatus waren signifikant mit dem Vorliegen von Mikrometastasen in den Mammaria-interna-Lymphknoten korreliert ( $p=0,018$ bzw. 0,001). Einer der 6 positiven Lymphknoten konnte sowohl mit H\&E- als auch mit IHC-Färbung dargestellt werden. Für die verbleibenden 5 Knoten von 4 Fällen konnte nur die IHC-Färbung Tumorzellen nachweisen. Insgesamt zeigten 8 der 83 Patientinnen (9,64\%) ohne Metastasen in den Mammaria-interna-Lymphknoten Fernmetastasen, während 2 der 5 Patientinnen (40\%) mit Metastasen in den Mammaria-interna-Lymphknoten innerhalb von 28 Monaten nach Operation Fernmetastasen aufwiesen. Schlussfolgerung: SSS kombiniert mit H\&E- bzw. IHC-Färbung ist beim Aufzeigen von Mikrometastasen effektiver als die routinemäßig eingesetzte, klassische SingleSlice-H\&E-Färbung.

For a long time, mastectomy was routinely used to establish local control. However women now have the option of breastconserving treatment followed by radiotherapy $[4,5]$. The lymph nodes outside the axilla, including the internal mammary lymph nodes (IMLNs), are not usually resected in the operation $[6,7]$. Recently sentinel lymph node biopsy has been identified as a new diagnostic procedure to determine

\section{KARGER \\ Fax +497614520714 \\ Information@Karger.de}

www.karger.com
(C) 2012 S. Karger GmbH, Freiburg

$1661-3791 / 12 / 0073-0216 \$ 38.00 / 0$

Accessible online at:

www.karger.com/brc
Dr. Jian Zeng

Department of Surgery

First Affiliated Hospital of Guangxi Medical University

Nanning, 530021, China

Tel. + 77 1535-0100, Fax -2627

zengian125@hotmail.com 
whether breast cancer has metastasized to axillary lymph nodes [8-11]. The sentinel lymph node is the hypothetical first lymph node or group of nodes reached by metastasizing cancer cells from a primary tumor [12]. However some reports have shown that sentinel lymph nodes can be located in the IMLNs [13, 14]. Early in 2002 Haryono et al. [15] reported that sentinel nodes in the IMLN chain were visualized on lymphoscintigraphy images and harvested by surgery from 2 patients. Unfortunately IMLNs outside the axilla are largely missed in modified radical mastectomy. At the same time micrometastases (MMs) are easily overlooked in routine pathological examination [16, 17]. Hence a more efficient method for detecting MMs in IMLNs is required. However studies on such pathological examination methods are still sparse $[18,19]$. In this study we explore examination methods for detecting MMs in IMLNs in order to pursue an improved management system for breast cancer.

\section{Patients and Methods}

\section{Patients}

The study included 88 cases who received a second and third ipsilateral parasternal IMLN biopsy from June 2006 to August 2008 at the Department of Gastrointestinal and Gland Surgery, First Affiliated Hospital of Guangxi Medical University, China. Inclusion criteria for this study were: i) breast cancer confirmed by histological examination, ii) negative IMLNs confirmed by hematoxylin and eosin (H\&E) staining, iii) no distant metastasis, and iv) age 18-65 years. Exclusion criteria were: i) treatment with preoperative neoadjuvant chemotherapy or endocrine therapy, ii) multiple tumor or bilateral breast cancer, and iii) number of axillary lymph nodes examined $<10$. The study protocol was approved by the Ethics Committee of Guangxi Medical University.

Step-Serial Sectioning

Paraffin-embedded IMLNs which had been confirmed negative for MMs by $\mathrm{H} \& \mathrm{E}$ staining were sliced at a spacing level of $40 \mu \mathrm{m} .4$ consecutive $4-\mu \mathrm{m}$ thick sections were cut at every level. Finally, 12 sections which had been placed on poly-L-lysine-coated slides and numbered consecutively were taken for each case.

\section{Detection}

Mouse anti-human cytokeratin-19 (CK-19) monoclonal antibody (A53-B/ A2.26, $\operatorname{IgG} 2 \alpha / \kappa)$, mouse anti-virus epithelial membrane antigen (EMA) monoclonal antibodies (E29, $\operatorname{IgG} 2 \alpha / \kappa)$, and the Elivision ${ }^{\mathrm{TM}}$ Plus detection kit (mouse/rabbit) were purchased from MaiXin Biotechnology Development (Fuzhou, China). The staining procedure was performed according to the manufacturer's instructions. For each level, the first section was used for H\&E staining, the second and third was for CK-19 and EMA immunohistochemistry (IHC) staining. The last section was used as a negative control.

\section{Reference Standard}

A DMR+Q550 pathological image analyzer (Leica, Germany) was used for pathological outcome evaluation. Atypical cancer cells were evaluated for MMs under high magnification $(\times 40)$, with comparisons made to the negative control. The clinical classification was that of the tumor-nodemetastasis (TNM) staging system of the American Joint Committee on Cancer/International Union Against Cancer [20]. According to the proto$\mathrm{col}$, lesions with a diameter of $0.2-2.0 \mathrm{~mm}$ were considered an MM; single tumor cells or those lesions of diameter $\leq 0.2 \mathrm{~mm}$ were defined as isolated tumor cells or clusters.

\section{Statistical Analysis}

All data were analyzed with the Statistical Package for the Social Sciences (SPSS) 13.0 software (SPSS, Chicago, IL, USA). Data are expressed as percentage or real number of each group. Numerous and continuous data were analyzed by Student's t test, and categorical data were analyzed by chi-square or Fisher's exact test. The consistency among the outcomes from various pathological detecting methods was evaluated using the kappa test. Significance was accepted at $\mathrm{p}<0.05$.

\section{Results}

\section{Clinicopathological Characteristics of the Patients}

Of the 88 cases that had been evaluated as negative for metastasis in IMLNs, 62 showed no sign of metastasis in the axillary lymph nodes. MMs in the axillary lymph nodes of the remaining 26 cases were identified as: 13 pN1, 5 pN2, and 8 pN3. Of these 26 cases, 5 (19.23\%) were found to be positive for MMs in the IMLNs using step-serial sectioning (SSS) combined with $\mathrm{H} \& \mathrm{E}$ and IHC staining. The mean age of the 88 patients was 50.33 years (range $26-76$ years). The histological grade and lymphovascular invasion status were significantly correlated with MMs in the IMLNs ( $p=0.018$ and 0.001 , respectively). However age, tumor size, tumor stage, $\mathrm{pN}$ stage, or triple-negative breast cancer were not related to MMs in the IMLNs $(\mathrm{p}=0.582,0.185,0.495$ and 0.081 , respectively).

\section{Comparison of the Efficiency in Detecting MMs between $H \& E$ and $I H C$}

Of the 135 IMLNs from 88 cases, 6 lymph nodes from 5 cases were observed to contain MMs. Of these 6 nodes, 1 node possessed MMs identified by both H\&E and IHC staining. The other 5 nodes from 4 cases showed only isolated tumor cells or clusters identified by IHC. Thus the MM detection rates by $\mathrm{H} \& \mathrm{E}$ and $\mathrm{IHC}$, or by IHC alone, were $1.14 \%(1 / 88)$ and $5.68 \%(5 / 88)$, respectively.

\section{Location and Pathological Features of MM}

It was observed that MMs were generally located at the subcapsular sinus, the nodal parenchyma, or both (figs. 1, 2). The tumor cells had large nuclear masses and obvious nucleosomal material. CK-19 was stained in brown and was localized in the cytoplasm, and EMA was stained in brown and localized both in the cytoplasm and plasma membrane. In invasive ductal carcinoma, cancer cells in MMs clump together, while in invasive lobular cancer these cells were dispersed in a diffuse pattern (fig. 3).

\section{Prognostic Analysis}

All 88 enrolled cases were followed up 18-56 months with a median follow-up time of 42 months. Eventually 8 of the 83 patients $(9.64 \%)$ without IMLN metastasis showed distant metastasis, while 2 of the 5 patients (40\%) with IMLN metastasis developed distant metastasis in the 28 months after operation. 


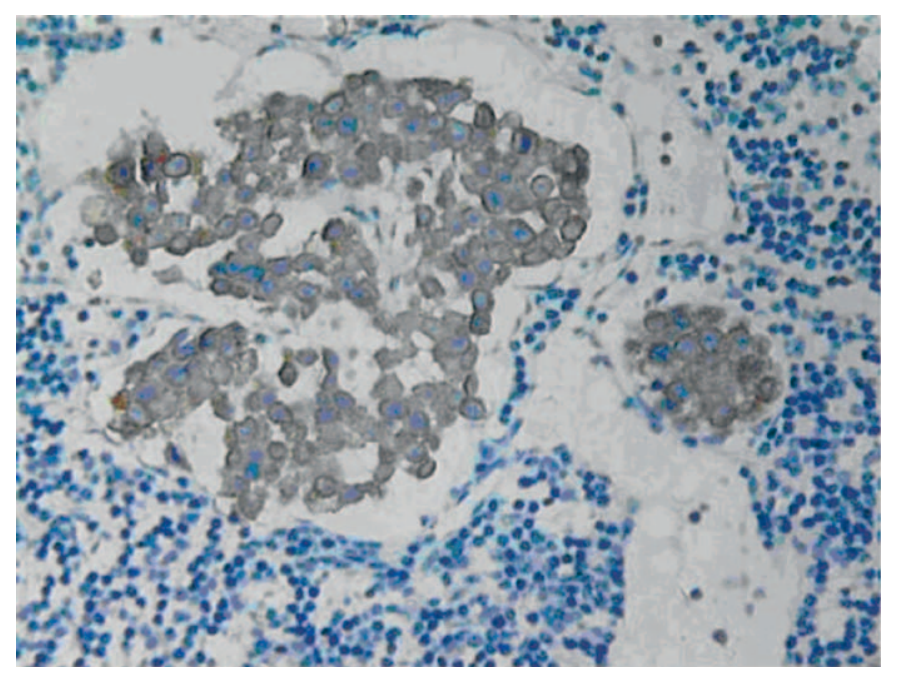

Fig. 1. Microscopy images of micrometastases in the parenchyma (CK$19, \times 400)$.

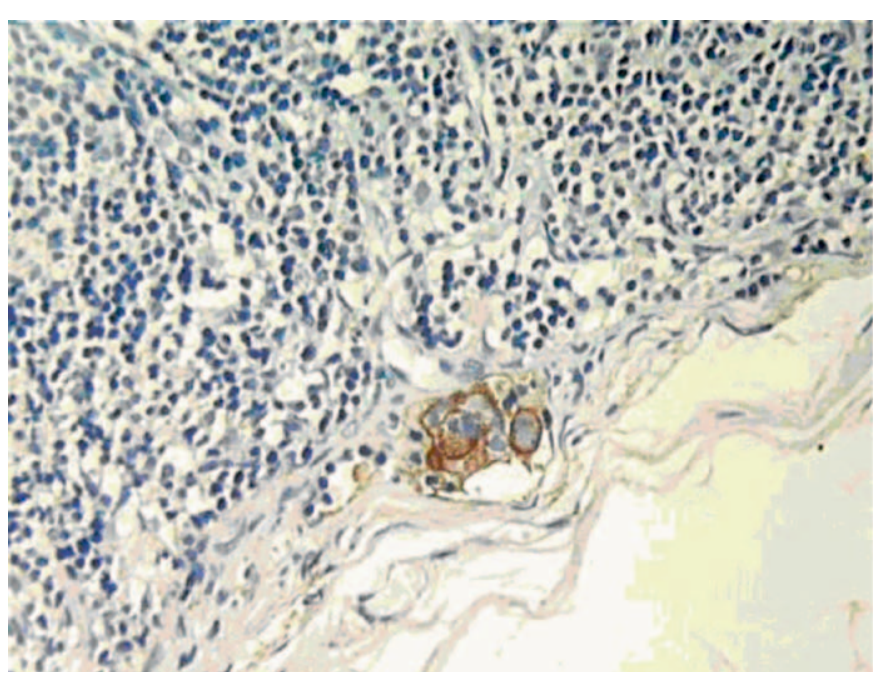

Fig. 2. Isolated tumor cells/clusters in the subcapsular sinuses (EMA, $\times 400)$.

Fig. 3. Isolated tumor cells dispersed in a diffuse pattern in infiltrating lobular carcinoma (EMA, left $\times 100$, central $\times 400$ ), but stained negatively with $\mathrm{H} \& \mathrm{E}$ (right).

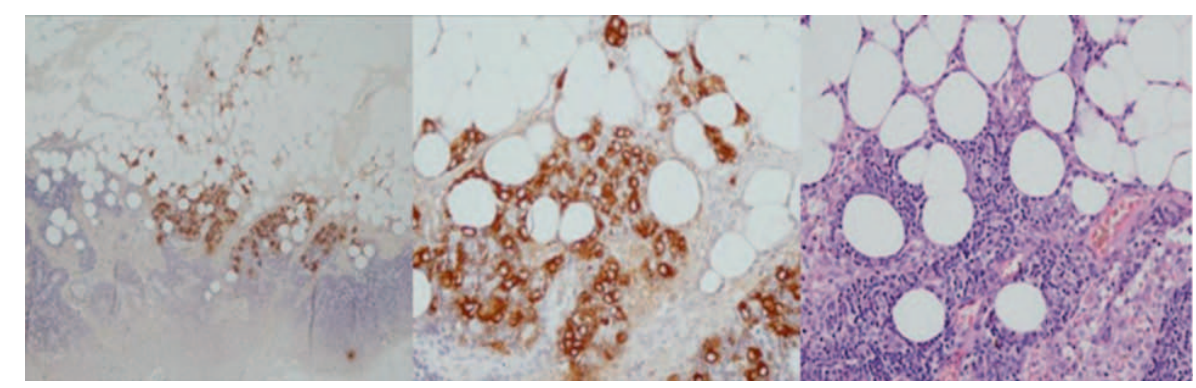

\section{Discussion}

In recent years there have been major advances in the treatment of breast cancer, which brings new hope for improved prognosis [21]. Although there are a number of treatment choices available, surgery is still the first-line treatment [22], and modified radical mastectomy is the major management method [23]. Sentinel lymph nodes have been increasingly found in IMLNs in conjunction with sentinel lymph node biopsies [24]. However IMLNs are not routinely resected in modified radical mastectomy. Furthermore MMs can be easily missed in routine pathological examinations. In this study we explored effective methods of pathology for detecting MMs in IMLNs in order to improve the management of breast cancer.

According to the National Health Service Breast Screening Programme and the Royal College of Pathologists [25], lymph nodes whose maximum size is greater than $5 \mathrm{~mm}$ should be sliced at intervals of approximately $3 \mathrm{~mm}$ or less, perpendicular to the long axis. This is an effective directive for serial sectioning to detect small metastatic deposits in lymph nodes. In fact, Dowlatshahi et al. [26] reported that tumor metastases were found in $12 \%$ of nodes surveyed when the sentinel lymph nodes were sectioned at 2-mm intervals and stained with $\mathrm{H} \& \mathrm{E}$, compared with the $58 \%$ positive rate when the same lymph nodes were serially sectioned at $0.25-\mathrm{mm}$ intervals and stained with anti-cytokeratin antibody [26]. Standard routine histological examination of axillary lymph nodes, including sentinel lymph nodes, often fails to detect lymph node metastases in cases of breast carcinoma. This deficit may be overcome by serial sectioning of the lymph nodes in their entirety, and staining with specific monoclonal antibodies.

In another study it was reported that serial sectioning of ipsilateral axillary lymph nodes which appeared to be diseasefree after routine histological examination revealed MMs in $9 \%$ of 921 breast cancer subjects [26]. These patients had a poor disease-free survival, and also overall survival, after the 5-year median follow-up compared with patients whose nodes remained negative on serial sectioning.

In the current study we examined 135 IMLNs by SSS in which no MMs had been found with routine H\&E staining. The outcome showed that IHC resulted in a higher MM detection rate compared to $\mathrm{H} \& \mathrm{E}$ staining in step-serial paraffin sections (5.68 vs. $1.14 \%$ ). However consistency of MM detection was weak in the 2 methods. Of the 135 nodes, MMs were observed in 6 nodes from 5 cases. In only 1 of the 6 nodes MMs were revealed by both H\&E and IHC, while the rest were detected by IHC alone. This could be due to the fact 
that the cancer cells in MMs are dispersed in a diffuse pattern in invasive lobular cancer. Thus IHC showed more efficiency than $H \& E$ in detecting these diffused cancer cells.

In this study CK-19 and EMA were employed for MM detection. 4 lymph nodes stained positive for both CK-19 and EMA. Furthermore $1 \mathrm{CK}-19$-positive lymph node and 1 EMA-positive lymph node were detected. As breast epithelial tissues are derived from the ectoderm, CK-19, as a cytokeratin marker, is widely used for the detection of lymph node MMs in breast cancer. However non-specific cross-reaction from dendritic-like cells and lymphoid cells can result in false-positive staining. Therefore a combined IHC staining could avoid false positives as well as improve efficiency in MM detection.

Serial sectioning increases the detection rate of MMs, and IHC facilitates detection of small metastatic deposits by direct labeling of the tumor cells. On the other hand, increasing the number of prepared sections will increase costs and put considerable strain on laboratory resources. In this study histological grade and lymphovascular invasion status were observed to be significantly correlated to MMs in the IMLNs. Therefore SSS for IMLNs is strongly recommended for cases of high histological grade and lymphovascular invasion.

\section{Conclusion}

Although in our study, patients with IMLN metastasis showed a higher incidence of distant metastasis compared with those without IMLN metastasis, the prognostic value of MMs is still controversial at present, especially because isolated malignant tumor cells often do not show malignant activity (such as proliferation or stromal reaction). Nonetheless, the prognostic value of lymph node MMs in IMLNs is being more and more recognized. SSS combined with $\mathrm{H} \& \mathrm{E}$ staining and IHC detection can produce satisfactory efficiency in detecting MMs that would otherwise be missed by routine single-slice $H \& E$ examination.

\section{Acknowledgement}

We thank Medjaden Bioscience Limited for assisting in the preparation of this manuscript.

\section{Disclosure Statement}

There are no ethical/legal conflicts associated with the article.

\section{References}

1 Anim JT, John B, et al.: Relationship between the expression of various markers and prognostic factors in breast cancer. Acta Histochem 2005;107:87-93.

2 Kasami M, Uematsu T, et al.: Comparison of estrogen receptor, progesterone receptor and Her-2 status in breast cancer pre- and post-neoadjuvant chemotherapy. Breast 2008;17:523-527.

3 Jemal A, Siegel R, et al.: Cancer statistics, 2007. CA Cancer J Clin 2007;57:43-66.

$\checkmark 4$ Gooiker GA, van Gijn W, et al.: A systematic review and meta-analysis of the volume-outcome relationship in the surgical treatment of breast cancer. Are breast cancer patients better of with a high volume provider? Eur J Surg Oncol 2010;36(suppl 1):S27-35.

5 Chen JJ, Wu J: Management strategy of earlystage breast cancer patients with a positive sentine lymph node: with or without axillary lymph node dissection. Crit Rev Oncol Hematol 2011;79:293301.

6 Noguchi S: Treatment strategy for metastatic breast cancer according to intrinsic subtype. Int $\mathrm{J}$ Clin Oncol 2010;15:333-334.

$\checkmark 7$ Schroen AT, Brenin DR: Breast cancer treatment beliefs and influences among surgeons in areas of scientific uncertainty. Am J Surg 2010;199:491-499.

8 Moffat FL Jr: Sentinel lymph node biopsy in breast cancer: cure and survival are paramount. J Surg Oncol 2010;102:109-110.

9 Sanguinetti A, Catania A, Docimo G, Avenia N: Radical axillary dissection in sentinel lymph node biopsy era: it's still a considerable technique in breast cancer management? G Chir 2010;31:344-346.

10 Fisher B, Anderson S, et al.: Twenty-year follow-up of a randomized trial comparing total mastectomy, lumpectomy, and lumpectomy plus irradiation for the treatment of invasive breast cancer. N Engl J Med 2002;347:1233-1241.

11 Veronesi U, Paganelli G, et al.: Sentinel-lymphnode biopsy as a staging procedure in breast cancer: update of a randomised controlled study. Lancet Oncol 2006;7:983-990.

12 Corben AD, Nehhozina T, Garg K, Vallejo CE, Brogi E: Endosalpingiosis in axillary lymph nodes: a possible pitfall in the staging of patients with breast carcinoma. Am J Surg Pathol 2010;34:12111216.

13 Cody HS 3rd: Clinical significance and management of extra-axillary sentinel lymph nodes: worthwhile or irrelevant? Surg Oncol Clin N Am 2010; 19:507-517.

14 Maalej M, Gargouri W, et al.: Internal mammary lymph node invasion in breast cancer: myth or reality? Tunis Med 2009;87:319-322.

15 Haryono SJ, Tanis PJ, et al.: Isolated internal mammary sentinel lymph node metastasis in two breast cancer patients. Int J Clin Oncol 2002;7:368-371.

16 Keshtgar MR, Chicken DW, et al.: Optical scanning for rapid intraoperative diagnosis of sentinel node metastases in breast cancer. Br J Surg 2010;97:1232-1239.

17 Yegiyants S, Romero LM, Haigh PI, DiFronzo LA: Completion axillary lymph node dissection not required for regional control in patients with breast cancer who have MMs in a sentinel node. Arch Surg. 2010;145:564-569.

18 Willis L, Alarcón T, et al.: Breast cancer dormancy can be maintained by small numbers of MMs. Cancer Res 2010;70:4310-4317.
19 Weaver DL: Pathology evaluation of sentinel lymph nodes in breast cancer: protocol recommendations and rationale. Mod Pathol 2010;23(suppl 2):S26-S32.

20 Wada N, Nakayama H, et al.: Prognostic value of the sixth edition AJCC/UICC TNM classification for differentiated thyroid carcinoma with extrathyroid extension. J Clin Endocrinol Metab 2007;92:215-218.

21 Petit JY, Clough K, et al.: Lipofilling in breast cancer patients: from surgical technique to oncologic point of view. Plast Reconstr Surg 2010;126:262e$263 \mathrm{e}$.

22 Biagioli MC, Harris EE: Accelerated partial breast irradiation: potential roles following breast-conserving surgery. Cancer Control 2010;17:191-204.

23 Akinci M, Cetin B, Aslan S, Kulacoglu H: Factors affecting seroma formation after mastectomy with full axillary dissection. Acta Chir Belg 2009;109:481-483.

24 Noushi F, Spillane AJ, Uren RF, Gebski V: Internal mammary node metastasis in breast cancer: predictive models to determine status and management algorithms. Eur J Surg Oncol 2010;36:16-22.

25 NHS Breast Screening Programme, Royal College of Pathologists: Pathology Reporting of Breast Disease. UK:NHSBSP; 2005. Report No. 58. www. cancerscreening.nhs.uk/breastscreen/publications/ nhsbsp58.html. Accessed October 31, 2010.

26 Dowlatshahi K, Wadhwani S, Alvarado R, Valadez C, Dieschbourg J: Interstitial laser therapy of breast fibroadenomas with 6 and 8 year followup. Breast J 2010;16:73-76. 